\begin{tabular}{|c|c|c|}
\hline \multirow{4}{*}{$\begin{array}{r}\text { Case Reports in } \\
\text { Gastroenterology }\end{array}$} & \multirow{2}{*}{\multicolumn{2}{|c|}{ Case Rep Gastroenterol 2018;12:497-503 }} \\
\hline & & \\
\hline & $\begin{array}{l}\text { DOI: 10.1159/000492212 } \\
\text { Published online: August 23, } 2018\end{array}$ & $\begin{array}{l}\text { ( } 2018 \text { The Author(s) } \\
\text { Published by S. Karger AG, Basel } \\
\text { www.karger.com/crg }\end{array}$ \\
\hline & $\begin{array}{l}\text { This article is licensed under the } \\
\text { International License (CC BY-NC) } \\
\text { Usage and distribution for commer }\end{array}$ & $\begin{array}{l}\text { nons Attribution-NonCommercial } 4.0 \\
\text { ger.com/Services/OpenAccessLicense). } \\
\text { uires written permission. }\end{array}$ \\
\hline
\end{tabular}

\title{
Peroral Endoscopic Myotomy in Diffuse Thickened Esophageal Wall in an Adolescent
}

\author{
Alexander A. Smirnov Aleksandr N. Burakov Aleksandr N. Shvetsov \\ Egor V. Blinov Kirill D. Semenikhin Nadezhda V. Konkina \\ Sergey Y. Dvoreckij \\ Pavlov First Saint Petersburg State Medical University, Saint Petersburg, Russia
}

\section{Keywords}

Diffuse esophageal wall thickening · Esophagus · Peroral endoscopic myotomy · Achalasia ·

Alport syndrome

\begin{abstract}
Achalasia is an extremely rare pathology in children. Peroral endoscopic myotomy (POEM) is the gold standard for the surgical treatment of achalasia in adults, but only a limited number of cases of achalasia treatment using POEM in children have been published in the literature. Sometimes, high-resolution manometry signs of achalasia can mimic diffuse esophageal leiomyoma. This case report represents the first known successful performance of POEM on a 15year-old female with diffuse thickening of the esophagus with signs and symptoms of achalasia and suspicion for Alport syndrome associated with diffuse esophageal leiomyoma.
\end{abstract}

(C) 2018 The Author(s)

Published by S. Karger AG, Basel

\section{Introduction}

Achalasia is an extremely rare pathology in children and occurs at a frequency of 0.020.11 per 100,000 children; however, it is a cause of delay in physical and mental development $[1,2]$. Heller's procedure is widely used to manage this disease. However, according to Meyer et al. [3], after analysis of surgical treatment in 42 children diagnosed with achalasia, relapse 


\section{Case Reports in Gastroenterology}

Case Rep Gastroenterol 2018;12:497-503

DOI: $10.1159 / 000492212$

(c) 2018 The Author(s). Published by S. Karger AG, Basel www.karger.com/crg

Smirnov et al.: Peroral Endoscopic Myotomy in Diffuse Thickened Esophageal Wall in an Adolescent

that required retreatment was diagnosed in 11 of 17 patients (65\%) after Heller's myotomy. In other patients, myotomy was performed as the second step, after administration of botulinum toxin and/or balloon dilatation, with relapse requiring repeated surgical intervention being observed in 10 cases. Peroral endoscopic myotomy (POEM) was developed to reduce traumatization and increase precision in the surgical treatment of achalasia [4]. It should be noted that several cases of achalasia treatment using POEM have been published in the literature $[5,6]$.

Summing up the interim results, it can be said that the results of traditional surgical treatment for achalasia in children cannot be considered completely satisfactory, primarily due to a rather high percentage of cases of relapse requiring retreatment. Meanwhile, results of POEM in adults are accompanied by a much smaller percentage of relapses, and, in children, single cases of endoscopic myotomy had good initial results. Thus, by extrapolation, it can be assumed that long-term results of POEM in children will be good.

\section{Case Report}

A 15-year-old female patient diagnosed with achalasia was admitted on March 13, 2017. On admission, the patient presented with persistent difficulty in swallowing solid and liquid food, which had occurred over the last 3 years (Eckhart scale score 7). Her history was remarkable for chronic glomerulonephritis and chronic renal failure. The patient underwent contrast esophagus fluoroscopy, which confirmed the cardiac achalasia diagnosis. High-resolution manometry (Solar GI; Medical Measurement Systems) of the esophagus showed results that were similar to type 2 achalasia (Fig. 1). However, we did not manage to pass the lower esophageal sphincter (LES) with the catheter because of strong contraction of the sphincter.

When performing the esophagoscopy, a significant expansion of the esophageal lumen was noted and significant resistance during the gastroscope passage through the LES. Following preoperative preparation, POEM was performed.

During the operation, pronounced esophageal mucosa thickness was detected, with fibrosis of the submucosa and extremely high pressure in the LES. Fifty-five minutes were spent on the creation of the initiating incision and submucosal tunnel. With the initiating dissection of the muscle layer, a significant thickness of the circular layer was noted, with presence of multidirectional fibers in basal sections (Fig. 2). In addition, there was a marked adhesion observed between the circular and longitudinal muscle layers. We dissected $10 \mathrm{~cm}$ of the circular muscle fibers above the esophagogastric junction (EGJ). Complete dissection of the muscular layer at the level of the EGJ was performed as well as $2 \mathrm{~cm}$ below the EGJ. We did not obtain a biopsy to confirm the diagnosis of diffuse leiomyoma because of the difficulties that had occurred during the operation, and we decided not to exacerbate the situation. The mucosal defect was closed with 6 endoscopic clips. The total operation time was $150 \mathrm{~min}$.

On postoperative day (POD) 2 , the patient noted a certain increase in pain in the operative region. To exclude the possibility of an esophageal perforation, the patient underwent a computed tomography (CT) of the thorax with oral contrast on the same day. The findings excluded perforation but revealed a right hydrothorax, which was successfully managed by pleural cavity puncture and Bülau drain. In addition, it was found that the wall of the esophagus was thickened up to $22 \mathrm{~mm}$ (Fig. 3).

On POD 4, contrast X-ray of the esophagus was performed, and the contrast medium entered the stomach lumen in small portions. Contrast leakage into the submucosal tunnel that was created during the operation was detected. Esophagoscopy showed a $3 \times 3 \mathrm{~mm}$ defect in 


\section{Case Reports in Gastroenterology}

Case Rep Gastroenterol 2018;12:497-503

DOI: $10.1159 / 000492212$

(c) 2018 The Author(s). Published by S. Karger AG, Basel www.karger.com/crg

Smirnov et al.: Peroral Endoscopic Myotomy in Diffuse Thickened Esophageal Wall in an Adolescent

the region of the initial incision; the edge and the bottom of the defect were covered with fibrin (Fig. 4). To drain the cavity, all clips were removed.

On POD 5, the patient was fed via nasoduodenal tubes and was treated conservatively. After that, the cavity was completely obliterated; on POD 9, the patient noted no pain and presented no symptoms of fever. The patient also noted the absence of dysphagia symptoms.

Eleven months after surgery, the patient was examined again. She had not subjective symptoms of recurrence (Eckhart scale score 1). Esophagoscopy was unremarkable. Chest CT showed an esophagus with thickened wall up to $9 \mathrm{~mm}$ (Fig. 5).

\section{Discussion}

This clinical case demonstrates the possibility of POEM in children, with good immediate and midterm results. During the operation, we faced several technical difficulties, some of which (thickened mucosal membrane, submucosal fibrosis) could be associated with chronic esophagitis.

On CT scan, we found a diffuse increase of the esophageal muscular layer thickness, reaching $14 \mathrm{~mm}$ in the LES region. This fact seemed unusual, and we reviewed the literature on this issue.

As early as 1916, Arthur J. Hall [7] described a case of death from progressive dysphagia involving a 17-year-old patient with concomitant renal pathology. On autopsy, thickening of the esophageal wall (up to $40 \mathrm{~mm}$ ) was found. According to the literature, diffuse leiomyoma of the esophagus can be observed in Alport syndrome, which is a hereditary nephropathy associated with sensorineural deafness and ocular abnormalities [8-10]. In the case described herein, we failed to perform genetic studies to confirm the diagnosis because of the lack of the equipment. Also, we did not obtain any biopsy to confirm the diagnosis of diffuse leiomyoma because of the difficulties that occurred during the operation. However, Hall [7] did not find thickening of the esophagus of $>5 \mathrm{~mm}$ in functional disorders and proposed this size as the cutoff point to differentiate diffuse leiomyomatosis from leiomyomatous-like pathology [11].

According to the literature, the most common treatment for diffuse esophageal leiomyoma in children has been esophageal resection, and only in a few cases has laparoscopic or open myotomy been performed. Bourque et al. [11] conducted a detailed review of the literature on the incidence of diffuse leiomyoma in children and found 22 cases, of which 2 were diagnosed only during autopsy. Based on the review, the authors concluded that, in contrast to adults, the diffuse type of leiomyoma prevails in children ( $91 \%$ of the cases). Radical treatment of this pathology may consider a resection of the esophagus and cardia with the imposition of gastroesophageal anastomosis, which was performed in 14 cases, and in 3 cases this approach led to the death of the children $[10,11]$.

POEM cannot be considered a radical operation. In our pediatric case, the application of POEM produced a significant clinical improvement, noted by the patient and confirmed by instrumental methods of investigation. Thus, POEM may be considered as an intermediatestage procedure in this patient population, allowing the patient to traverse adolescence without the phenomena of dysphagia. In the available literature, we have not found any case of POEM application for this pathology.

In conclusion, the immediate and midterm clinical and instrumental results of POEM in a child with diffuse thickened esophageal wall with symptoms and signs of achalasia can be considered satisfactory. In case of recurrence of symptoms, the next step in the treatment should be resection of the esophagus. In children with symptoms of achalasia, CT of the thorax should 
be included in the preoperative examination to define whether there is a thickened esophageal wall.

\section{Statement of Ethics}

This case report did not require institutional review board approval, since only approved common procedures were performed on the patient, and only fully anonymized data were used for the report.

\section{Disclosure Statement}

None of the authors have any conflicts of interest pertaining to this publication, and none have any competing interests to declare.

\section{References}

1 Mayberry JF, Mayell MJ. Epidemiological study of achalasia in children. Gut. 1988 Jan;29(1):90-93.

2 Hussain SZ, Thomas R, Tolia V. A review of achalasia in 33 children. Dig Dis Sci. 2002 Nov;47(11):2538-43.

3 Meyer A, Catto-Smith A, Crameri J, Simpson D, Alex G, Hardikar W et al. Achalasia: outcome in children. J Gastroenterol Hepatol. 2017 Feb;32(2):395-400.

4 Inoue H, Minami H, Kobayashi Y, Sato Y, Kaga M, Suzuki M et al. Peroral endoscopic myotomy (POEM) for esophageal achalasia. Endoscopy. 2010 Apr;42(4):265-71.

5 Familiari P, Marchese M, Gigante G, Boskoski I, Tringali A, Perri V et al. Peroral endoscopic myotomy for the treatment of achalasia in children. J Pediatr Gastroenterol Nutr. 2013 Dec;57(6):794-7.

6 Maselli R, Inoue H, Misawa M, Ikeda H, Hosoya T, Onimaru M et al. Peroral endoscopic myotomy (POEM) in a 3-year-old girl with severe growth retardation, achalasia, and Down syndrome. Endoscopy. 2012;44(S 02 Suppl 2 UCTN):E285-7.

7 Hall A. A case of diffuse fibromyoma of the oesophagus, causing dysphagia and death. QJM. 1916 July;os9(36):409-28.

8 Van Loo A, Vanholder R, Buytaert I, De Paepe A, Praet M, Elewaut A et al. Alport syndrome and diffuse leiomyomatosis with major morbid events presenting at adult age. Nephrol Dial Transplant. 1997 Apr;12(4):776-80.

9 Cochat P, Guibaud P, Garcia Torres R, Roussel B, Guarner V, Larbre F. Diffuse leiomyomatosis in Alport syndrome. J Pediatr. 1988 Aug;113(2):339-43.

10 Dagbert F, Pelascini E, Pasquer A, Gincul R, Mion F, Poncet G et al. Extensive preoperative workup in diffuse esophageal leiomyomatosis associated with Alport syndrome influences surgical treatment: A case report. Int J Surg Case Rep. 2015 Apr;10:183-6.

11 Bourque MD, Spigland N, Bensoussan AL, Collin PP, Saguem MH, Brochu P et al. Esophageal leiomyoma in children: two case reports and review of the literature. J Pediatr Surg. 1989 Oct;24(10):1103-7. 


\section{Case Reports in Gastroenterology}

Case Rep Gastroenterol 2018;12:497-503

DOI: $10.1159 / 000492212$

(c) 2018 The Author(s). Published by S. Karger AG, Basel www.karger.com/crg

Smirnov et al.: Peroral Endoscopic Myotomy in Diffuse Thickened Esophageal Wall in an Adolescent

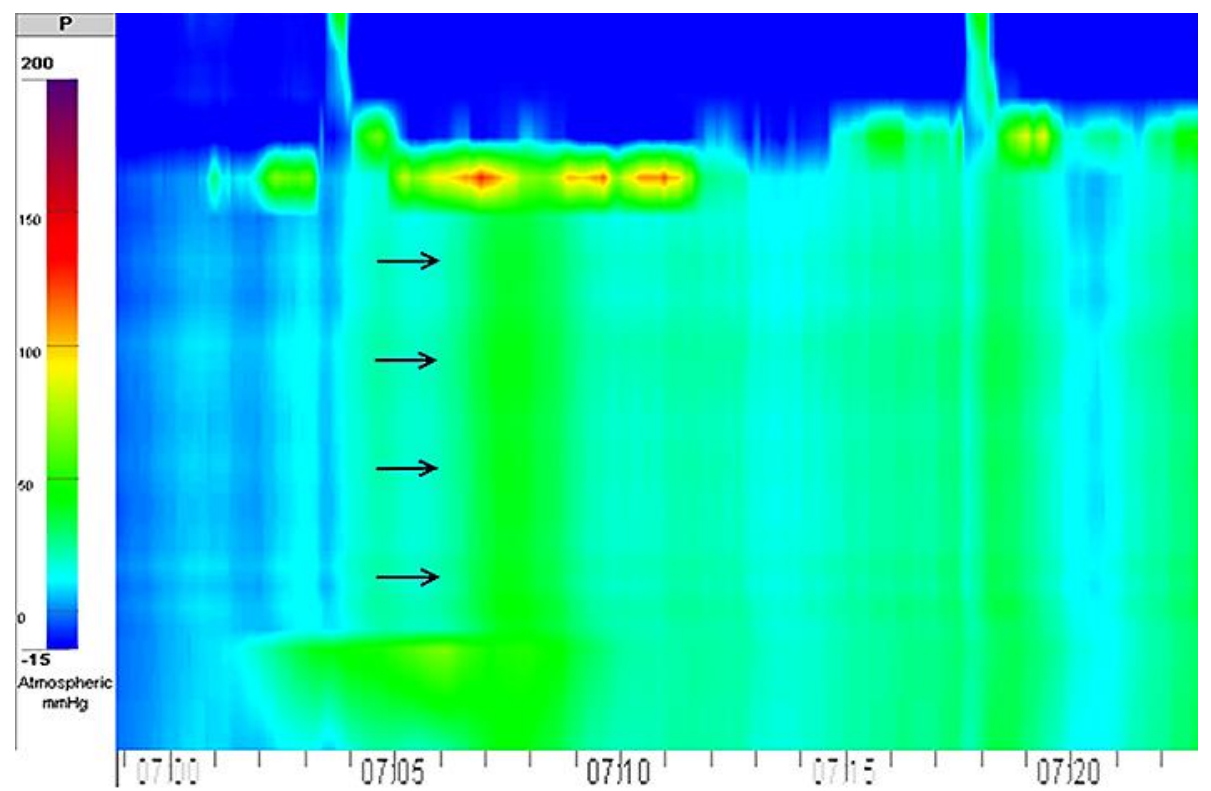

Fig. 1. High-resolution manometry of the patient's esophagus. Manometric signs of achalasia type II were found (panesophageal pressurization is denoted by black arrows).

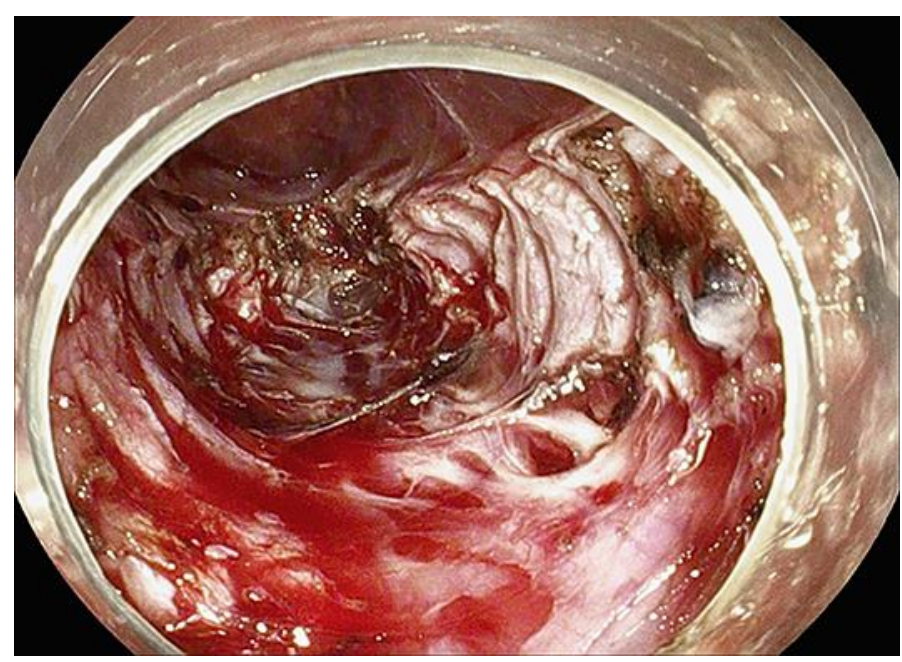

Fig. 2. Myotomy of the thickened circular muscle of the patient's esophagus, showing the view from the level of the muscular layer. 


\section{Case Reports in Gastroenterology}

\begin{tabular}{l|l}
\hline Case Rep Gastroenterol 2018;12:497-503 \\
\hline DOI: 10.1159/000492212 & $\begin{array}{l}\text { ○ 2018 The Author(s). Published by S. Karger AG, Basel } \\
\text { www.karger.com/crg }\end{array}$ \\
\hline
\end{tabular}

www.karger.com/crg

Smirnov et al.: Peroral Endoscopic Myotomy in Diffuse Thickened Esophageal Wall in an Adolescent

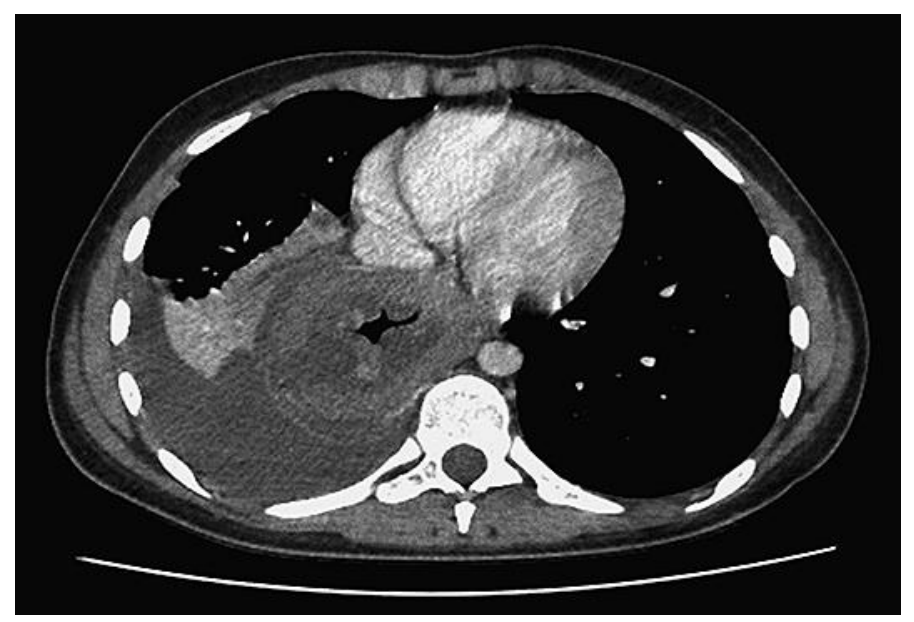

Fig. 3. Thickening of the esophageal wall in the patient, detected by computed tomography of the thorax with oral contrast. The thickening was up to $22 \mathrm{~mm}$.

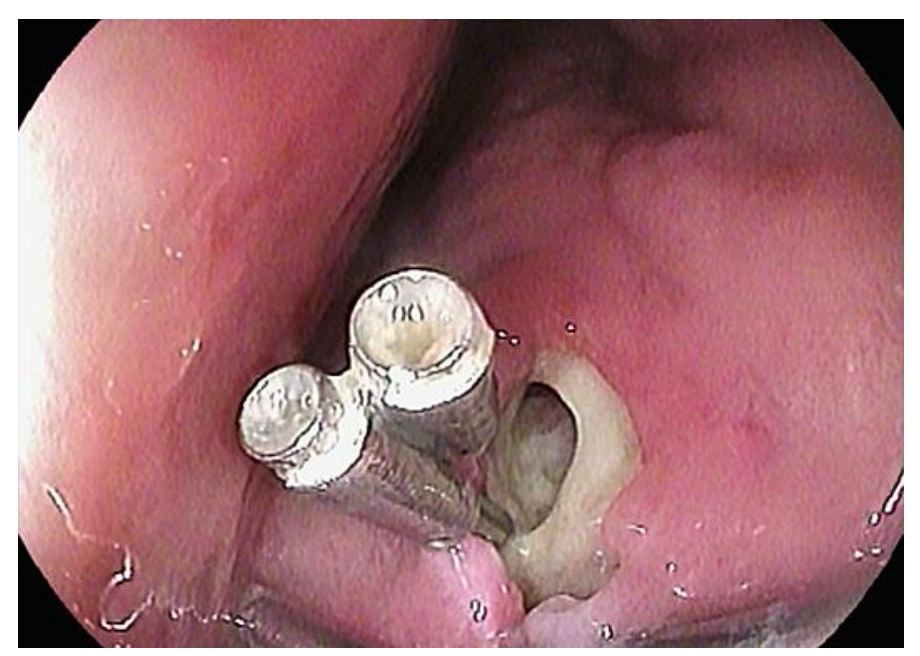

Fig. 4. Defect of $3 \times 3 \mathrm{~mm}$ in the region of the initial incision. The area had been previously closed with clips. The edge and the bottom of the defect are covered with fibrin. 


\section{Case Reports in Gastroenterology}

\begin{tabular}{l|l}
\hline Case Rep Gastroenterol 2018;12:497-503 \\
\hline DOI: 10.1159/000492212 & $\begin{array}{l}\text { @ 2018 The Author(s). Published by S. Karger AG, Basel } \\
\text { www.karger.com/crg }\end{array}$ \\
\hline
\end{tabular}

www.karger.com/crg

Smirnov et al.: Peroral Endoscopic Myotomy in Diffuse Thickened Esophageal Wall in an Adolescent

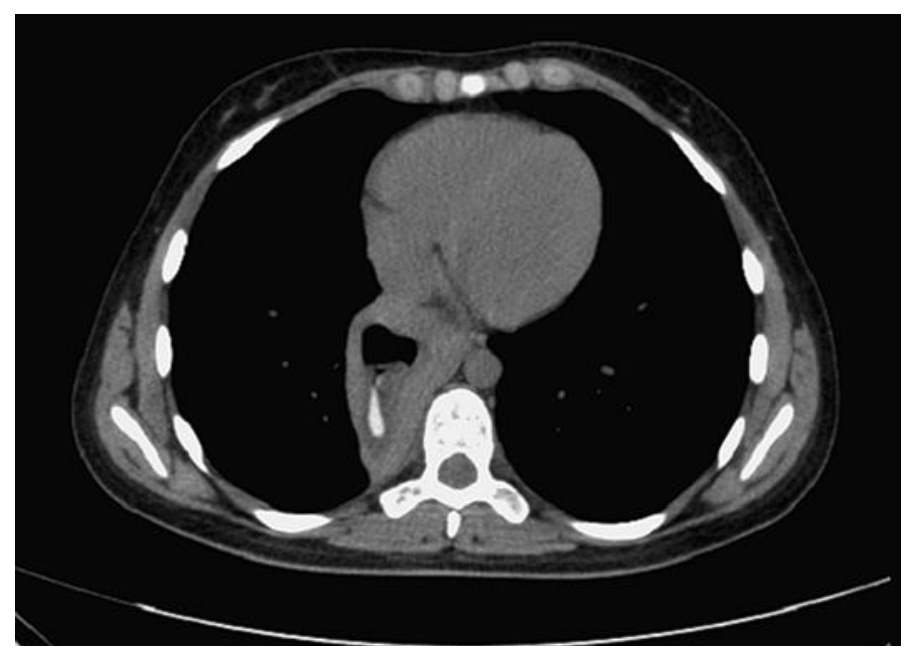

Fig. 5. Chest computed tomography 11 months after surgery. Thickening of the esophageal wall remains up to $9 \mathrm{~mm}$. 